zuclopenthixol in the treatment of schizophrenia with substance abuse comorbidity. Can J Psychiatry 2006; 51: 531-9.

7 National Institute for Health and Clinical Excellence. NICE Implementation Uptake Report: Atypical Antipsychotic Drugs for the Treatment of Schizophrenia. NICE, 2008 (http://www.nice.org.uk/ media/410/E9/ImplUptakeReportAtypicalAntipsychotics.pdf).

8 Guy W (1976) ECDEU Assessment Manual for Psychopharmacology: 218-22. National Institute of Mental Health, 1976

9 World Health Organization. The ICD-10 Classification of Mental and Behavioural Disorders: Clinical Descriptions and Diagnostic Guidelines. WHO, 1992.

10 British Medical Association, Royal Pharmaceutical Society of Great Britain. British National Formulary (55th edn) (March issue). BMJ Books \& Pharmaceutical Press, 2008.

11 Barbee JG, Conrad EJ, Jamhour NJ. The effectiveness of olanzapine, risperidone, quetiapine and ziprasidone as augmentation agents in treatment-resistant major depressive disorder. J Clin Psychiatry 2004, 65: $975-81$

12 Centorrino F, Fogarty KV, Cimbolli P, Salvatore P, Thompson TA, Sani G et al. Aripiprazole: initial clinical experience with 142 hospitalized psychiatric patients. J Psychiatr Pract 2005; 11: 241-7.

13 Shajahan $P$, MacRae $A$, Bashir $M$, Taylor $M$. Who responds to aripiprazole in clinical practice? An observational study of combination versus monotherapy. J Psychopharmacol 2008; 22: 778-83.
14 Stroup TS, Lieberman JA, McEvoy JP, Swartz MS, Davis SM Capuano GA, et al. Effectiveness of olanzapine, quetiapine, and risperidone in patients with chronic schizophrenia after discontinuing perphenazine: a CATIE study. Am J Psychiatry 2007; 164: 415-27.

15 Jones PB, Barnes TR, Davies L, Dunn G, Lloyd H, Hayhurst KP, et al. Randomized controlled trial of the effect on quality of life of second- vs first-generation antipsychotic drugs in schizophrenia: Cost Utility of the Latest Antipsychotic Drugs in Schizophrenia Study (CUtLASS 1). Arch Gen Psychiatry 2006; 63: 1079-87.

16 Kahn RS, Fleischhacker WW, Boter H, Davidson M, Vergouwe Y, Keet IP, et al. Effectiveness of antipsychotic drugs in first-episode schizophrenia and schizophreniform disorder: an open randomised clinical trial. Lancet 2008; 371: 1085-97.

17 Rabinowitz J, Lichtenberg P, Kaplan Z, Mark M, Nahon, D, Davidson M Rehospitalization rates of chronically ill schizophrenic patients discharged on a regimen of risperidone, olanzapine, or conventional antipsychotics. Am J Psychiatry 2001; 158: 266-9.

18 Tiihonen J, Walhbeck K, Lonnqvist J, Klaukka T, loannidis JP, Volavka J, et al. Effectiveness of antipsychotic treatments in a nationwide cohor of patients in community care after first hospitalisation due to schizophrenia and schizoaffective disorder: observational follow-up study. BMJ 2006; 333: 224-7.

19 Shajahan P, Keith S, Majiiga C, Murphy J, MacRae A, Bashir M, et al. Comparing the effectiveness of aripiprazole and quetiapine in schizophrenia and related psychoses. J Clin Psychiatry 2009; 70: 692-8.

\title{
Experience of support time and recovery workers in promoting WRAP
}

\author{
Laura Hill, ${ }^{1}$ Glenn Roberts, ${ }^{1}$ Wilson Igbrude ${ }^{2}$
}

The Psychiatrist (2010), 34, 279-284, doi: 10.1192/pb.bp.108.024539

${ }^{1}$ Wonford House Hospital, Exeter, UK; ${ }^{2}$ Department of Psychiatry, University of Missouri Hospital, USA

Correspondence to Glenn Roberts (glenn.roberts@devonptnrs.nhs.uk)
Aims and method Supporting self-management is a core ambition of progressive mental health services, but little is known about how to achieve this. Support time and recovery (STaR) workers are routinely taught the Wellness Recovery Action Plan (WRAP). This study explores their capacity to support self-management using WRAP.

Results The audited STaR trainees had introduced an average of nine service users each to WRAP. There was a trend for those with personal experience of mental illness to introduce more clients to WRAP and even more so for those who had used WRAP themselves. Qualitative analysis suggested a range of factors that may mediate whether people engage with self-management or not.

Clinical implications The capacity of STaR workers and others to support people in self-management may depend on more than knowledge of self-management methods and having personal experience of mental health problems and services. Important factors may also include specific experience of the methods introduced, ongoing training, accountability and supervision.

Declaration of interest None.
Give a man a fish, feed him for a day,

Teach a man to fish, feed him for his life.

Lao Tsu, 600 BC

Supporting people in becoming skilled at looking after themselves was recently reaffirmed as 'one of the key pillars of the NHS Improvement Plan vision for a patient-centred care system'. There is growing evidence in physical healthcare that people with long-term conditions find selfcare and self-management to be effective in improving quality of life and promoting appropriate use of services. ${ }^{2}$ 
Supporting self-care is a specific work stream arising from the national service framework for long-term conditions linked to the Department of Health's Expert Patient programme. ${ }^{3,4}$ Self-care and self-management have an established role in recovery-based practice, ${ }^{5}$ and are in line with the expectations laid out in the White Paper Our Health, Our Care, Our Say ${ }^{6}$ and in the Department of Health's guidance Supporting People with Long-Term Conditions to Self Care. ${ }^{7}$ Additionally, the Royal College of Psychiatrists, along with other medical Royal Colleges, is now required to include competencies in supporting people in self-care in their core curricula.

There is every indication that self-care is 'an idea whose time has come, 8 and the past 10 years have seen the development of a wide range of supports and programmes for self-management of mental health (Box 1). Self-care and self-management approaches are increasingly popular but of uncertain value. An international review ${ }^{9}$ found comparatively little experience of self-management methods in mental health settings, no real evidence of impact, and no real clarity on how self-management could be promoted in mental health services. The need for 'further research on successful methods of supporting self-management and recovery' identified in the Royal College of Psychiatrists' Fair Deal campaign ${ }^{10}$ remains a call that has yet to be answered.

The Wellness Recovery Action Plan (WRAP) is, internationally, the most popular self-management tool for maintaining mental health. ${ }^{11}$ Although there is a large and growing body of anecdotal reports of benefit, ${ }^{12-14}$ it is largely under-researched. One of the few studies of outcome in using WRAP $^{15}$ reported beneficial changes (significant improvement in self-reported symptoms, recovery, hopefulness and self-advocacy), but it was uncontrolled and described self-reported outcomes over a very limited time (1 month). Another study found WRAP significantly associated with an increase in participants' hope for recovery, taking responsibility for their own wellness and having a support system in place. ${ }^{16}$

The WRAP tool is a structured approach that is written, owned and used by the individual. It is constantly updated in the light of a person's experience of what works for them. It supports a process of structured reflection leading to action plans that an individual uses to modify or overcome adverse experiences and promote well-being. This requires a personal commitment and active engagement to staying well and an ambition to be in control of one's own life. It involves developing a 'wellness toolbox' of skills and strategies, planned responses to increasing levels of difficulty and distress, and a crisis plan (advanced directive) as a guide to be followed in the event of recurring severe mental health problems.

The UK mental health organisations' Future Vision Coalition ${ }^{17}$ highlights WRAP as a key system that supports 'people with mental distress to work with professionals to identify and prioritise their own personal goals for recovery' and states that 'tools of this kind should be much more widely used in everyday practice in mental health services'. Following various training initiatives, WRAP has been used extensively in the south-west of England (www. recoverydevon.co.uk), is promoted by the Black Wellness
Box 1 Supportive resources for self-care and selfmanagement

Information

- Mental Health Information from the Royal College of Psychiatrists: www.rcpsych.ac.uk/mentalhealthinformation.aspx

- British Association for Behavioural and Cognitive Psychotherapies: www.babcp.com

- The Northumberland series of self-help leaflets: www.ntw.nhs.uk/pic/?p=selfhelp

Guidance

- Glasgow Steps, stress related topics: www.glasgowsteps.com/ self-help

- The Expert Patient Programme for self-care in long-term conditions: www.expertpatients.co.uk

- Promoting Optimal Self Care: www.swirl.nhs.uk/resource/164

- FearFighter: www.fearfighter.com

- The Mood Gym: www.moodgym.anu.edu.au

- MDF The BiPolar Organisation (Manic Depressive Fellowship) www.mdf.org.uk/index.aspx?o=56979

Support for self-defined self-management

- The Wellness Recovery Action Plan: www.mentalhealthrecovery.com; www.recoverydevon.co.uk

- Pathways to Recovery: A Strengths Recovery Self-Help Workbook. By P Ridgway, D McDiarmid, L Davidson, J Bayes, S Ratzlaff. Kansas University School of Social Welfare, 2006

- Rethink's recovery and self-management project: www.rethink.org/living_with_mental_illness/recovery_and_ self_management/index.html

- Recovery In-Sight, lifestyle development programme for people with bipolar disorder: www.recoveryin-sight.com

Online self-care planning

- Blue Salmon: www.lemosandcrane.co.uk/bluesalmon_trial/

- WRAP planning: www.cequick.com/myeln/copeland/ default.asp

- Living Life to the Full: www.livinglifetothefullinteractive.com

Initiative (www.blackwellness.co.uk) and forms the core of personal recovery planning at South West London and St George's Mental Health NHS Trust. ${ }^{18}$ It has also influenced other illness-specific approaches such as Recovery In-Sight for bipolar disorder (www.recoveryin-sight.com) and there is currently a major national training programme aimed at developing a cohort of WRAP trainers in Ireland, funded by the Department of Justice, Equality and Law Reform (www.imhrec.ie).

Wellness Recovery Action Plan originated from a service user perspective and is largely delivered by peers (people who have experience of mental distress and who may have used services). The benefits of peer-delivered services and supports have been summarised as including: ${ }^{19}$

- positive role modelling ('If you can, maybe I can too')

- emotional and social support and empathic connection 
- authenticity of the trainers having experience of using methods they are teaching

- practical and usable information and strategies from those who have used them

- a sense of normalcy through interacting with others with shared or common experience.

The inception of support time and recovery (STaR) workers followed recommendations from the Workforce Action Team convened by MPs to consider the implications of the national service framework for adult mental health. ${ }^{20}$ For the first time, a group of workers were explicitly recruited for their personal qualities rather than professional qualifications, and their personal experience of mental health problems and services was also valued. It was intended that they would work in a variety of statutory and non-statutory settings, provide practical support, promote independence, and support service users in selfcare with the aim of empowering them to lead 'ordinary lives'. Support time and recovery workers were the first and so far only group of mental health workers to be systematically trained in the ten essential shared capabilities for mental health practice, which included training in recovery and supported self-management with WRAP. ${ }^{14,21}$

\section{Method}

\section{Setting}

Devon was an early adopter of the national STaR training initiative and has one of the best networks of STaR workers. ${ }^{5,10,22}$ Over 300 people from a wide variety of backgrounds have so far participated in training, which was offered free on an unselected basis to all who were interested. This included service users and carers, workers for voluntary and third-sector agencies, housing support workers and unqualified workers in statutory services undergoing conversion to become STaR workers (see STaR section of www.recoverydevon.co.uk). There was no specific offer or expectation that people who did STaR training would subsequently be employed as STaR workers. The STaR programme offered an entry-level experience for people engaged with, or contemplating, mental health work and strongly represented the values and principles of recovery-oriented approaches which are being broadly promoted in Devon. ${ }^{10}$

The STaR initiative in Devon therefore provided an opportunity to see how training unqualified healthcare workers in a specific self-management tool benefits people using WRAP and what helped and hindered that learning. We hypothesised that people with STaR training who also had personal experience of using WRAP, and therefore worked as peers, would be more able to offer that support to others. The study was commissioned by the Devon STaR steering group, with whom we have collaborated on the study design and delivery.

\section{Sample}

The questionnaire was sent with a self-addressed return envelope to all participants in the first 2 years of STaR training in Devon ( $n=128)$, and followed by a reminder letter and another copy of the questionnaire 6 weeks later. The request to participate was signed by the lead for STaR training in Devon, who was known personally to all participants. Trainees were geographically dispersed and worked for a wide range of statutory and non-statutory employers, were unemployed or independent. A subsequent telephone check revealed that only 71 were still contactable at the addresses they had originally given and they were our study sample.

\section{Data collection}

The questionnaire comprised quantitative and qualitative questions. The former covered basic demographic details, training experience, subsequent confidence in WRAP and experience of introducing WRAP to others. The latter asked three open-ended questions on what helped or hindered engagement with WRAP and what could improve this.

1 Thinking about those who did take up WRAP and use it, what helped - what are the key issues?

2 Thinking of those who did not take it up or use it, what hindered this - what are the key issues?

3 If the overall aim is to enable WRAP to be put into practice and to encourage people we are working with to develop their own WRAP plans as a support for selfmanagement, what would enable this to happen?

\section{Analysis}

The quantitative results were analysed using SPSS for Mac OS and free-text responses were thematically analysed by two researchers (L.H. and W.I.). The themes and the percentage of respondents positively identifying each theme were recorded. Any disagreements were resolved through discussion or categorised as ambiguous (uncoded). We were supported in both analyses by researchers highly experienced in quantitative and qualitative methods.

\section{Results}

\section{Respondents}

Out of the total 71 questionnaires sent out, 60 were returned completed (85\%); 46 respondents (77\%) were female, which was representative of the study sample as a whole. Forty-four of the respondents $(73 \%)$ were over 40 years old. Just over $40 \%$ stated they had personal experience of a mental health problem and $33 \%$ used a WRAP plan themselves. Of those respondents who had completed the training, half were subsequently employed in STaR roles, a third of whom reported personal experience of mental health problems.

\section{Training and confidence}

Seven respondents had been trained in WRAP within the previous 6 months, 22 within 6-12 months and 25 over the past 12 months; 6 respondents had not been trained in WRAP despite this being core to STaR training. A third of respondents described feeling very confident at introducing WRAP to service users and a further half stated they were moderately confident. 


\section{Introducing others to WRAP}

At the time of the study, respondents stated they had introduced a total of 477 service users to WRAP (mean=9, range 0-80), of whom 207 (43\%) had taken it up. There was no significant difference between individuals currently employed as STaR workers and others in how many service users they introduced to WRAP, and we did not find any association between age of STaR worker and numbers introduced. There was a non-significant trend for those who had personal experience of mental health problems to introduce more people to WRAP. Those who used WRAP themselves introduced an average of 14 people compared with 6 for those who did not.

\section{What helped and what hindered WRAP take up?}

A number of themes emerged during analysis of the freetext responses regarding WRAP take up. The themes and percentage of respondents positively identifying each theme are included in Tables 1-3. Engagement with WRAP is mediated by a range of factors, but with emphasis on the benefits of a structured approach, introduced with adequate support and at the right time for the individual.

\section{Limitations}

A surprisingly high number of people who had attended STaR courses had moved on from their initial contact address and were subsequently unavailable to comment on their experience. The study may have been more powerful with a control group who had no previous experience of mental health problems and supporting others in selfmanagement, but as a naturalistic rather than experimental study this was not possible. The anonymity of the study design did not allow us to clarify the meanings of some of the responses or follow up non-responders. Neither can we comment on the effectiveness of WRAP as a self-management tool, or compare it with other approaches to selfmanagement.

\section{Discussion}

Self-management is not another treatment but a means of people becoming more active in their own recovery, taking up more responsibility for their experience and regaining more authority and control over their lives. The Wellness Recovery Action Plan is a simple, sensible and structured tool; supporting people in self-management by introducing them to WRAP is a seemingly straightforward, if elusive, goal.

In this initial group of STaR trainees there was a wide variation in the experience of engaging people in WRAP, with seven trainees introducing none. It would appear that there is an appreciable gap between providing people with a theoretical grounding in a self-management tool and them subsequently introducing it to others, hence a continuing need to understand the obstacles between learning principles and changing practice. Clear and practical steps may be needed by organisations, professions and individuals who wish to make the shift towards recovery-oriented services. ${ }^{11,23}$
Table 1 What helped engagement with WRAP?

Theme

$\%$

Individuals valued the structured approach of WRAP and

the identification of triggers

Individuals with good insight and understanding about

their mental health were more likely to participate in producing and using a WRAP plan

Offering choice and giving control to the individual made them more willing to engage in producing a WRAP plan

Support from workers to help the individual produce a WRAP plan

A person-centred approach which is tailored to meet the individual's needs

Introducing the WRAP at an appropriate time or stage in the illness when the individual is able to engage with the process and explore what works for them Uncoded

WRAP, Wellness Recovery Action Plan

Table 2 What hindered engagement with WRAP?

Theme

$\%$

WRAP introduced at the wrong time for the individual to find it useful

Individual does not believe it will be useful

Individual does not seem to have sufficient motivation to create a WRAP

ndividual lacks understanding as to why a WRAP plan may be beneficial or how to use it 22

Individual is fearful of what will be involved 18

Too few workers to support people with the creation and implementation of their WRAP plans

Individual concerned about the implications of recovery through engaging with WRAP - for example, loss of benefits and additional responsibilities 12

Features of the WRAP document such as length and time taken to complete

12

Uncoded 7

WRAP, Wellness Recovery Action Plan

Table 3 What could improve engagement with WRAP?

Theme $\%$

Additional support for the person from individual workers, mental health services and non-statutory organisations 23

Involvement of individuals and peer support to offer advice from lived experience

Training and supervision for workers on recovery from long-term conditions and self-management

Publicity to raise awareness within the general population and combat the stigma of mental illness

Early introduction of WRAP to anyone presenting to psychiatric services

Keeping the paperwork, language and concepts simple 5

WRAP, Wellness Recovery Action Plan. 
Engaging and supporting people in self-care is a required competency within the emerging core curriculum for psychiatrists $^{24}$ and an acknowledged key skill in recovery-based practice. It has been observed ${ }^{25,26}$ that for practitioners to support people in self-management, we as practitioners may need to give up some of our power and authority and create more opportunities for personal choice. There are strong theoretical grounds for considering that support for self-management may be most effective when offered by those who have experienced and overcome similar problems themselves, a trend that also appeared in our study. There may be reciprocity between self-management and peer support such that those who have found such measures valuable themselves may be more confident and skilled at introducing them to others. ${ }^{27}$ This is the guiding premise of the Expert Patient Programme where 'experts by experience' rather than (just) 'experts by training' may be more effective and acceptable recovery coaches to service users. ${ }^{4}$ It also underpins the ambitious Irish national WRAP training programme (Irish Mental Health and Recovery Education Consortium), which aims to develop its cohort of WRAP trainers from people who have themselves already learnt and used WRAP. ${ }^{19}$

The unexpected finding in this study that many of those who had participated in training had moved on from their initial contact address or affiliation with non-statutory groups during the period covered (2 years) highlights specific workforce issues and has significant implications for turning training into services. Offering training in an open way to unselected applicants under no obligation to subsequently use their skills may be seen as a positive contribution to a broad development of a recovery culture but clearly has different implications for workforce planning. Trainees' subsequent performance may also be influenced by the expectations placed upon them, for although STaR trainees were taught WRAP, they were not specifically expected to be 'WRAP facilitators' and much was left to individual interpretation of the STaR role in a wide variety of personal and service provider settings. Taking an inclusive and undemanding stance to trainees may fail to deliver the hoped for benefits from training but indicates a need to reconsider fidelity issues to the STaR role, as well as a need for ongoing support and supervision.

Our study also highlights the importance of individualised, person-centred care. Workers identified insight, understanding and motivation as key mediators to participation in WRAP. This is unsurprising given the complexity of WRAP and underlines the advice that formulating a selfmanagement plan is best done when someone is comparatively well and able to reflect on their experience.

Although self-care and self-management are prominent and valued goals of progressive services, the available models and evidence of successful outcome is partial, provisional and largely anecdotal. This study is set at the most superficial and preliminary level - can people who have been taught a self-management tool (WRAP) pass it on? Our findings of the modest transfer of learning from the inaugural cohort of STaR trainees are disappointing. However, despite its limitations, the study usefully highlights some of the complexities that need to be considered if we are to learn how to more effectively engage people as active participants in their own recovery. Additionally, it suggests that considerable care and ongoing attention need to be given to training, support and supervision if the ambitious gains are to be realised in practice.

\section{Acknowledgements}

Thanks to Ann Ley and Tobit Emmens for support in data analysis and to Laurie Davidson, STaR lead in Devon.

\section{About the authors}

Laura Hill is Specialist Registrar in Psychiatric Rehabilitation and Recovery, Wonford House Hospital, Exeter, UK, Glenn Roberts is Consultant in Psychiatric Rehabilitation and Recovery, Wonford House Hospital, Exeter, UK, and Wilson Igbrude is Psychiatric Resident, Department of Psychiatry, University of Missouri Hospital, Columbia, Missouri, USA.

\section{References}

1 Cayton H. Self Care. Department of Health, 2007 (http://www. dh.gov.uk/en/Healthcare/Longtermconditions/DH_4128529).

2 Foster M. Self-care: a working partnership. BMA News 2008; 22 March: 9.

3 Department of Health. The National Service Framework for Long-Term Conditions. Department of Health, 2005 (http://www.dh.gov.uk/en/ Publicationsandstatistics/Publications/PublicationsPolicyandGuidance/ DH_4105361).

4 Department of Health. The Expert Patient: A New Approach to Chronic Disease Management for the 21st Century. Department of Health, 2001.

5 Care Services Improvement Partnership, Royal College of Psychiatrists, Social Care Institute for Excellence. A Common Purpose: Recovery in Future Mental Health Services. SCIE, 2007.

6 Department of Health. Our Health, Our Care, Our Say. A New Direction for Community Services (White Paper). Department of Health, 2006 (http:// www.dh.gov.uk/PolicyAndGuidance/OrganisationPolicy/Modernisation/ OurHealthOurCareOurSay/fs/en).

7 Department of Health. Supporting People with Long-Term Conditions to Self Care. Department of Health, 2006 (http://www.dh.gov.uk/en/ Publicationsandstatistics/Publications/PublicationsPolicyAndGuidance/ Browsable/DH_4100317)

8 Cottam H, Leadbeater C. Health: Co-Creating Services. The Design Council, 2004

9 Singh D, Ham C. Improving Care for People with Long-Term Conditions: A Review of UK and International Frameworks. University of Birmingham, 2006

10 Royal College of Psychiatrists. Fair Deal Manifesto. Royal College of Psychiatrists, 2008

11 Slade M. 100 Ways to Support Recovery: A Guide for Mental Health Professionals. Rethink, 2009.

12 Deegan G. Discovering recovery. Psychiatr Rehabil J 2003; 26: 368-76

13 Copeland ME. The WRAP Story: First Person Accounts of Personal and System Recovery and Transformation. Peach Press, 2008.

14 Copeland ME. Wellness Recovery Action Plan. Sefton Recovery Group, 2005

15 Cook J, Copeland ME, Hamilton MH, Jonikas JA, Razzano L, Floyd C, et al. Initial outcomes of a mental illness self-management program based on Wellness Recovery Action Planning. Psychiatr Serv 2009; 60: 246-9.

16 Cook J. Mental illness self-management through wellness recovery action planning. Mary Edlen Copeland, 2009 (http://www mentalhealthrecovery.com/wrap_research_findings_judithcook.php).

17 Future Vision Coalition. A Future Vision for Mental Health. Future Vision Coalition, 2009 (http://www.futurevisionformentalhealth.org.uk/ A_future_vision_for_mental_health.pdf). 
18 Perkins R, Rinaldi M. A Guide to Planning Your Own Recovery. South West London and St George's Mental Health NHS Trust, 2007.

19 Corrigan P, Muser K, Bond G, Drake R, Soloman P. Peer services and supports. In Principles and Practice of Psychiatric Rehabilitation: 346-58. Guilford Press, 2008

20 Department of Health. National Service Framework for Mental Health: Modern Standards and Service Models. Department of Health, 1999.

21 Hope R. The Ten Essential Shared Capabilities: A Framework for the Whole of the Mental Health Workforce. Department of Health, 2004

22 Slade M. Personal Recovery and Mental Illness: A Guide for Mental Health Professionals. Cambridge University Press, 2009: 231-3.
23 Shepherd G, Boardman J, Slade M. Making Recovery a Reality. Sainsbury Centre for Mental Health, 2008.

24 Royal College of Psychiatrists. A Competency Based Curriculum for Specialist Training in Psychiatry. Royal College of Psychiatrists, 2009 (http://www.rcpsych.ac.uk/training/curriculum2009.aspx).

25 Roberts G, Hollins S. Recovery: our common purpose? Adv Psychiatr Treat 2007; 13: 397-9.

26 Roberts G, Dorkins E, Wooldridge J, Hewis E. Detained - what's my choice? Part 1: Discussion. Adv Psychiatr Treat 2008; 14: 172-80.

27 Copeland M, Mead S. WRAP and Peer Support: A Guide to Individual, Group and Program Development. Peach Press, 2003.

\title{
The Mental Capacity Act 2005: review of mental capacity assessment in people with proximal femoral fracture
}

\author{
P. Guyver, ${ }^{1}$ P. Hindle, ${ }^{1}$ J. Harrison, ${ }^{2}$ N. Jain, ${ }^{1}$ M. Brinsden ${ }^{1}$
}

The Psychiatrist (2010), 34, 284-286, doi: 10.1192/pb.bp.109.026757

${ }^{1}$ Derriford Hospital, Plymouth; ${ }^{2}$ HMNB Portsmouth

Correspondence to J. Harrison (james.harrison650@mod.uk)

\begin{abstract}
Aims and method To ascertain whether patients with proximal femoral fractures were being correctly assessed in line with the Mental Capacity Act 2005 . Fifty people admitted with proximal femoral fractures were audited to assess whether they had given consent to treatment in accordance with the Act. A Mental Capacity Act 2005 guidance and assessment form was then introduced accompanied by staff training. $A$ re-audit was undertaken to assess the impact.
\end{abstract}

Results The initial audit showed that only one person (2\%) had been properly assessed. The re-audit demonstrated that the use of the Mental Capacity Act 2005 assessment form ensured correct assessment.

Clinical implications Our findings suggest the form is a useful tool in the documentation and assessment of an individual's capacity under the Mental Capacity Act.

Declaration of interest None.
It is now over a year since the implementation of the Mental Capacity Act 2005 in England and Wales. This new legislation and its impact on clinicians has been described elsewhere, ${ }^{1}$ however one of the key requirements of the Act is that: 'The person who assesses an individual's capacity to make a decision will usually be the person who is directly concerned with the individual at the time the decision needs to be made'. ${ }^{2}$ The act of giving consent to any procedure performed in a healthcare setting is now subject to the Mental Capacity Act and its requirements, and a legal framework exists to ensure that both the decision maker and the patient have rights and responsibilities.

The direct responsibility of the clinician performing a procedure has also subtly changed under the Act; now, this decision maker has to take responsibility for the decision even if he seeks advice from another professional (such as a psychiatrist) when assessing the patient's capacity. This change therefore makes it a requirement for all clinicians to be able to assess, describe and document capacity with regard to the specific procedures. When confronted with an individual requiring a surgical procedure for instance, the Mental Capacity Act requires that the consenting doctor fully assesses the person before deciding upon a specific course of treatment. This assessment process is clearly described within the Act and essentially consists of two stages.

1 Does the person have an impairment of, or a disturbance in the functioning of their mind or brain? If the answer to this is no then the patient is assumed under the Act not to lack capacity, and so a procedure of informed consent can be instigated. The Code of Practice ${ }^{2}$ lists examples of conditions that may lead to this impairment 